\title{
No Creative Person is an Island: Organisational Culture, ACAdemic Project-based Creativity, ANd THE Mediating ROLE OF INTRAORGANISATIONAL SOCIAL TIES
}

\author{
Frien G.A. van Kessel \\ International Business School, Fontys University of Applied Sciences Venlo, The Netherlands \\ Leon A.G. Oerlemans \\ Department of Organization Studies and Centre for Innovation Research, \\ Tilburg University, The Netherlands \\ Graduate School of Technology Management, University of Pretoria, South Africa \\ Saskia A.M. van Stroe-Biezen \\ International Business School, Fontys University of Applied Sciences Venlo, The Netherlands \\ Accepted: October 2013
}

\begin{abstract}
This paper examines the relationship between perceptions of organisational culture, academics' social embeddedness and their creative paper project output. It argues that the extent to which researchers working on paper projects are socially embedded through social ties with colleagues inside and outside their academic department (but within the same university) is a causal step linking organisational values and norms to creative outputs. This study does not, however, find support for the proposed mediating effects. Instead, results indicate that three organisational culture dimensions - i.e. performance orientation, environmental orientation and innovation support - affect employees' creative project output through their social embeddedness outside the department (but within their own university). As the organisational culture and social embeddedness of employees outside the department are both contextual factors that matter (either indirectly or directly) for the generation of creative project outputs by researchers, this study concludes that "no creative person and no project is an island".
\end{abstract}

Key words: organizational culture, social embeddedness, creative output

JEL: O15, 13, M14

1

\section{Introduction}

In rapidly changing, competitive and turbulent environments, organisations increasingly recognise creativity as one of the key factors in innovation and long-term organisational survival (Mathisen, Einarsen, Jørstad \& Brønnick, 2004). Traditionally, the main focus in creativity research has been on individual qualities (McLean, 2005). Various studies have sought to explain why some people are more creative than others, and have focused on the extent to which personality traits, individual skills and experiences can influence creativity (Guilford,

\section{0; Amabile, 1988).}

More recently, the focus of research has shifted towards the influences of the organisational (project) contexts in which these individuals work (e.g. Amabile, Conti, Coon, Lazenby \& Herron, 1996; Oldham \& Cummings, 1996). The Questions addressed in these studies relate to the influence of organisational phenomena such as leadership (Tierney, Farmer \& Graen 1999), job complexity, extrinsic rewards (Cummings \& Oldham, 1997) and organisational culture (Isaksen, Lauer, Ekvall \& Britz, 2001) on individual creativity.

This study argues that "no creative person is an island". In other words, the creative project 
output of employees, which in this case encompasses the quality and quantity of papers published by academic researchers, may be affected by the context in which these employees operate. On the one hand, creative output may be affected by employees' perceptions of the organisational culture. On the other hand, it is argued that employees are socially embedded in the organisation through a number of social ties with colleagues within or outside their own work units. This study considers perceptions of organisational culture and the social embeddedness of employees as two different aspects of the organisational context. According to Amabile and Mueller (2008), creative output is highest when both aspects of the organisational context support it.

De Brentani and Kleinschmidt (2004) argue for a deeper understanding of the softer dimensions which are part of the internal context of organisations and which affect individual creativity. That is, a key challenge for scholars and practitioners at organisations is to understand and stimulate the development of organisational cultures that support creativity (Andriopoulos, 2001). Organisational culture is regarded as one of the primary determinants of creativity (Andriopoulos, 2001; Dombrowski, Kim, Desouza, Braganza, Papagari, Baloh \& Jha, S, 2007) because it provides an overarching frame of reference that aligns and guides employee behaviour (Khazanchi, Lewis \& Boyer, 2007). This study examines the relationship between organisational culture (as an important aspect of the organisational context of projects) and creativity, where the latter is considered as an output in terms of novel and useful ideas presented in (published) papers produced by academic researchers working on projects.

Furthermore, it is increasingly recognised that the generation of novel and useful ideas may well be a product of direct interaction between employees (Watson, 2007). PerrySmith (2006) suggests that social ties with colleagues are important antecedents to creative output. For example, these social ties allow employees to gather information by discussing research in their field with colleagues, or to evaluate and probe new ideas with colleagues (Amabile \& Mueller, 2008). Oh and colleagues (2004) also highlight the importance of social embeddedness in the generation of novel and useful ideas. In this respect, they refer to social capital, that is the extent to which employees have ties with colleagues within the social structure of their own work unit, or within the broader social structure of the organisation at large (Oh, Chung \& Labianca, 2004). An employee's social ties with colleagues within his or her own work unit provide that employee with a sounding board that enhances or deepens his or her understanding of the field. This may facilitate the generation of novel and useful ideas, products or solutions (Perry-Smith \& Shalley, 2003). In other words, the social ties provide access to colleagues with similar knowledge resources. On the other hand, employees with social ties outside the work unit but within the same organisation are expected to have greater access to a more diverse set of knowledge and information resources (Pelled, Eisenhardt \& Xin 1999). Hence, being socially embedded within or outside the work unit may offer unique opportunities as it makes resources available to employees (Oh et al., 2004). Sethia (1995) states that, through social ties, employees may be able to achieve greater creative outputs than if they had relied only on their own resources.

However, since organisational culture is a frame of reference that provides norms and guidelines for behaviour and activities in the organisation (O'Reilly, Chatman \& Caldwell 1991; Khazanchi et al., 2007), it could also influence the extent to which employees are socially embedded through the number of social ties they have with colleagues. In turn, the number of social ties could affect an employee's creativity (Perry-Smith, 2006; Oh et al., 2004). Nevertheless, many studies ignore the relationship between organisational culture and employees' social embeddedness (Drazin, Kazanjian \& Glynn 2008). The present study argues that the number of social ties that employees have with others is a causal step linking organisational values and norms to creative outputs. Hence, the purpose of this study is to examine the extent to which employees' perceptions of organisational culture affect both creative output and social embeddedness and, most importantly, to determine to what extent the social embeddedness of employees mediates between perceptions of organisational culture and creative output. In 
so doing, this study contributes to research on organisational antecedents for creativity. It examines the effects of two different aspects of the organisational context, namely perceived organisational culture and social embeddedness, on creative output, as well as the interrelation between these contextual aspects.

The main research question in this study is: "To what extent does the social embeddedness of employees mediate the relationship between employees' perceptions of organisational culture and their creative outputs?" We begin by discussing why creative outputs in terms of the production of papers by academic researchers are considered to be the result of project-based production. We then proceed to discuss the literature on creativity and organisational culture. We discuss how perceptions of organisational culture may affect the creative output of employees. Next, employees' social ties and their relationships with creative output are discussed. This is followed by a description of the research setting and the measurement of variables. Next, we present and discuss the findings of this study, and the conclusions drawn from the findings. Lastly, we discuss some limitations and future research directions.

2

\section{Why academic papers are project-based productions}

Project-based production encompasses the generation of high-value and unique products, systems, networks, capital goods or constructs within a defined set of resources, goals and time constraints (Hobday, 2000). Project-based production has become the norm in creative work, as evidenced by advertising campaigns, fashion or trade shows, and art exhibits (Christopherson \& Van Jaarsveld, 2005). However, the outputs of project-based production often differ in terms of customisation, specifications or the extent to which they are coproduced (Whitley, 2006). Such differences have significant implications for the management of projects and their ability to generate distinctive capabilities and knowledge (Casper \& Whitley, 2004). According to Whitley (2006), two underlying dimensions relating to the development of capabilities and knowledge are especially important in project-based productions. These are (1) the extent to which projects focus on developing unusual, sometimes one-off, products or services and (2) the extent to which the organisation of expertise, tasks and roles is predictable and stable over projects. The first dimension suggests that project-based productions may differ in their singularity, and contrasts those project-based productions that generate a single or small number of unique outputs with those producing (a series of) similar or related outputs. The second dimension suggests that project-based productions may also differ in the degree of stability of work roles and skills both within a project and over the course of several projects. This dimension differentiates project-based productions that organise tasks and skills in novel and projectspecific ways from those that rely on preestablished competences and routines for working together (Whitley, 2006). In other words, some project-based outputs are produced by individuals undertaking a series of projects along with others (simultaneously or iteratively), who work together over a period of time and develop collective routines for managing their activities, while others are produced by bringing together the different and variable skills and roles necessary for the project on hand. According to Whitley (2006), projectbased productions with varying degrees of singularity can be accomplished with different degrees of stability. For example, some projectbased productions may lead to unique outputs, produced by individuals participating in a single project, while others may result in less unique outputs produced by participants working together on multiple projects at the same time.

Using Whitley's (2006) criteria, to what extent can the production of academic papers be regarded as project-based production? Firstly, concerning the singularity criterion, it should be noted that academic papers commonly and explicitly state what the addressed knowledge gap is and what contribution the study makes to the research field. To qualify for publication in a (high-ranking) journal, these academic papers must offer a certain degree of novelty and uniqueness. Thus, although academic papers may vary in their degree of novelty and uniqueness, they are expected to make some unique contribution to the research field and therefore meet the singularity criterion for 
project-based productions. Secondly, regarding the role separation and stability criterion, it is maintained that the production of academic papers may vary in respect of the degree of stability of work roles and skills. That is, some papers are produced by bringing together the different and variable skills and roles necessary for the research at hand, while others are produced by academic researchers undertaking a series of projects in collaboration with others, with whom they collaborate for a limited period while developing collective routines for managing their activities. In the former type, the coordination of tasks and skills is more complex, but the flexibility enables the researchers to adapt their working processes with ease. The latter method is a more stable way of coordinating research activities which places greater reliance on pre-established competences, identities and routines for working together. This form of collaboration often occurs where research groups consist of a cluster of authors working on multiple academic papers. This suggests that the production of academic papers can also vary in respect of stability of work roles and skills, and therefore meets Whitley's (2006) second criterion for projectbased productions. Hence, as both criteria are met, this study concludes that academic papers are project-based productions.

\section{3}

\section{Theory and hypotheses}

\subsection{Creative output}

Creativity is considered one of the key factors that contribute to long-term organisational survival and success (Mathisen et al., 2004; DiLiello \& Houghton, 2006). To enhance their chances of long-term survival, organisations focus on supporting individual creativity in the workplace (Amabile, 1988; Woodman, Sawyer \& Griffin, 1993). Although some approach individual creativity as a process involving several stages or sub-processes ${ }^{1}$ and contributing to the production of creative outputs (Drazin et al., 2008), most studies refer to individual creativity as either creative potential or creative output (DiLiello \& Houghton, 2006). Creative potential refers to an individual's creative traits, skills or abilities that lead to the production of acts, items and instances of novelty; creative output is seen as the generation of creative ideas, products or processes (Wierenga \& Van Bruggen, 1998).

In this study an output perspective on individual creativity is adopted. An individual's output is often considered to be creative if it is novel or new, as well as useful or valuable to the organisation (Amabile, 1983). In definitions of creativity, the terms "novel" and "useful" are widely used. In this study creativity is defined as the production of novel and useful ideas by individuals in any domain (Amabile et al., 1996; Woodman et al., 1993). Hence, in order to be considered creative, an individual's outputs must have some level of uniqueness compared to other ideas, but should not be so extreme that adoption or implementation by the organisation is not feasible (Perry-Smith \& Shalley, 2003).

A closely related concept, often referred to in creativity literature, is innovation, which can be defined as the generation, development and successful implementation of new ideas (Hurley, 1995; Amabile et al., 1996). Although both concepts refer to the generation of new ideas, the definitions of creativity and innovation reveal a clear conceptual difference. In addition to the generation of new ideas, innovation includes the development and implementation of these ideas, which illustrates that all innovations begin with the production of a new and useful idea (Amabile et al., 1996). With regard to creativity and innovation, Twiss (1992) emphasises the role of project management, and argues that intraorganisational factors such as the presence of a project champion, the evaluation systems and the project management play an important role in the implementation of creative ideas. This suggests that, although there is a clear distinction between creativity and innovation, creativity appears to be a necessary condition for innovation (Twiss, 1992; Mathisen et al., 2004). Hence, studies seem to assume that what is good for innovation may be good for creativity as well (Martins \& Terblanche, 2003; McLean, 2005; Martins \& Martins, 2007).

According to DiLiello and Houghton (2006), the intraorganisational context can either facilitate or impede the generation of novel and useful ideas. These authors state that in supportive 
contexts, employees are more likely to actually generate creative ideas and creative solutions to problems. More particularly, recent studies have called for further investigation of the organisational culture (e.g. De Brentani \& Kleinschmidt, 2004) and social ties (e.g. PerrySmith, 2006) as contextual antecedents of individual creative output.

\subsection{Organisational culture and organisational climate}

Several authors have particularly emphasised the importance of organisational culture in creating an institutional context in which creativity flourishes (Pheysey, 1993; Ahmed, 1998; Martins \& Terblanche, 2003). In this study, organisational culture is defined as the taken-for-granted values, underlying assumptions, expectations, collective memories and definitions present in the organisation, which impart a sense of identity, provide unspoken guidelines on how to get along and enhance the stability of the social system to which members of the organisation belong (Cameron \& Quinn, 1999: 14).

Studies that approach organisational culture as a component of the internal organisational environment have referred to its similarities or dissimilarities to organisational climate (e.g. Schein, 1990; Denison, 1996; Ahmed, 1998; Schneider, 2000). There has been some debate on the conceptual similarities and dissimilarities (see Denison, 1996, for an extensive discussion), but the latest literature largely agrees that organisational culture and climate are similar concepts that reflect different perspectives on the organisational context (e.g. Schein, 1990; Denison, 1996; Ahmed, 1998; Schneider, 2000). Organisational culture and organisational climate are treated as similar concepts in this study. Organisational climate is taken to reflect the patterns of behaviour of employees, while organisational culture is seen as referring to the underlying context of values, beliefs and norms (Denison, 1996).

Although organisational culture is likely to exert an influence on the extent to which novel and useful ideas are generated (Ekvall, 1996) and valued as something desirable (Locke \& Kirkpatrick, 1995), relatively little empirical work has been done on the relationship between organisational culture and creativity
(McLean, 2005). Only a small number of scholars have explored this relationship empirically (Amabile et al., 1996; Tesluk, Farr \& Klein, 1997). In contrast, more studies have focused on the dimensions of a climate conducive to creativity (Ekvall, 1996; West, 1990; Isaksen \& Lauer, 2002; Patterson, West, Shackleton, Dawson, Lawthom, Maitlis, Robinson \& Wallace, 2005).

As organisational culture and organisational climate are perceived as conceptually similar, dimensions of organisational climate are expected to reflect a manifestation of organisational culture. In fact, Hurley (1995) states that insights regarding the potential effect of organisational culture on creativity and innovation have emerged from studies on organisational climate. According to Mathisen and colleagues (2004), the most commonly applied and validated model used in these studies is the Team Climate Inventory (TCI) developed by West (1990). Moreover, these studies have been conducted mainly on the individual level by taking into account the individual's perception of the organisational context (Agrell \& Gustafson, 1994; Anderson \& West, 1998; Ragazzoni, Baiardi, Zotti, Anderson \& West, 2002). This study therefore argues that the TCI can be an appropriate framework for examining employee perceptions of the organisational culture.

\subsection{Organisational culture and creative output}

The TCI refers to "vision", "participative safety", "task orientation" and "support for innovation" as the four dimensions essential for stimulating creativity and innovation. According to West (1990), vision can be defined as an idea of a valued outcome which represents a higher order goal and a motivating force at work (p 310). With regard to creativity, this definition suggests that a vision gives employees an idea that creativity is valued in the organisation. West (1990) states that organisational cultures supporting creativity and innovation are characterised by a focus on clearly defined and realistic objectives. Thus, "vision" incorporates the extent to which having a clear vision is valued in the organisation. This clear vision may improve employees' commitment to creative work (Mathisen et al., 2004), as goal direction 
can motivate employees to generate creative output (West, 1990).

A second dimension of the TCI model is participative safety, which consists of two components, namely participativeness and safety. Participativeness pertains to the involvement of employees in decision making through the influence they have and the sharing of information (West, 1990). In addition, safety enables employees to propose new ideas and solutions to problems in a nonjudgmental environment (Anderson \& West, 1998). The more employee participation in decision making is valued, the more likely employees will be to invest in the outcomes of those decisions, as well as in the generation of ideas for new and improved working methods (Anderson \& West, 1998).

The third dimension, task orientation, is about commitment to high standards of performance (Kivimäki \& Elovainio, 1999). It relates to the critical appraisal or basic questioning of the way in which the work is done. More specifically, this dimension deals with the exploration of opposing positions, the open-minded consideration and understanding of opposing positions, and the willingness to integrate ideas into a highly satisfactory solution (Anderson \& West, 1998). Creative performance requires employees to reflect critically upon their tasks, objectives, strategies and processes (Mathisen et al., 2004) in an environment that supports the continuous adoption of improvements (Anderson \& West, 1998). That is, if employees are to be creative, maximisation of task performance quality must be valued (West, 1990).

The final dimension of the TCI model is innovation support, which concerns the enacted support in the organisation for attempts to introduce new and improved ways of doing things. Enacted support is about the degree to which employees are expected to introduce new and improved procedures into the organisation, and the approval and practical support they receive (Mathisen et al., 2004). Innovation support therefore reflects the extent to which the development and implementation of new ideas is valued in the organisation, and is considered to be a necessary condition for creativity and innovation to occur (Mathisen et al., 2004).
The literature on organisational culture and climate as associated with creativity and innovation points to the importance of an orientation towards an organisation's external environment, in addition to the four TCI dimensions. According to Ahmed (1998), environmental orientation is about the extent to which internal change occurs in response to external conditions. Fey and Denison (2003) focus on customer orientation, and define it as the extent to which an organisation is driven by its customers and is capable of change. Deshpandé and colleagues (1993) also refer to customer orientation, but define it as that part of the organisational culture that represents the beliefs that put changing customer interests first, while not excluding those of other stakeholders. Schein (2004) makes the general statement that organisations should be aware of their major economic stakeholders. In addition to customers, external stakeholders such as investors and stockholders, suppliers of raw materials, the community and the government should also be taken into account. These definitions commonly refer to the extent to which internal adaptability to changes in the external environment is valued in the organisation. Moreover, those organisations that focus on and are sensitive towards changing external stakeholder needs are more likely to have a sense of urgency about changing traditional working methods (Kotter, 2008). An urgent desire to change and the associated uncertainty prompt organisations to find creative solutions to problems (Ford \& Kuenzi, 2008). In other words, organisational cultures characterised by a strong orientation towards the external environment are more likely to enhance the generation of creative output. Environmental orientation is therefore considered as a fifth dimension of organisational culture associated with creativity and innovation.

As the TCI was developed largely for the purpose of assessing the organisational environment for creativity and innovation (West, 1990), and as the literature associated with creativity also refers to environmental orientation as an important dimension of organisational culture (Deshpandé et al., 1993; Ahmed, 1998; Martins \& Terblanche, 2003), all five dimensions of organisational culture presented in this 
section are expected to contribute to creativity. We have therefore generated the following hypotheses:

Hypothesis 1: The more employees perceive the present organisational culture to be characterised by a strong vision orientation, participative safety, task orientation, innovation support and environmental orientation, the higher their creative output.

\subsection{Social embeddedness and creative output}

While organisational culture is an important contextual factor, creative output may also result from social interactions between employees (Shalley \& Gilson, 2004) as they combine and integrate existing but varying pools of knowledge and ideas (Leenders, Van Engelen \& Kratzer, 2003). Employees' creative output may well be affected by the network of interactions of which they are part (Agrell \& Gustafson, 1994). Moreover, the generation of novel and useful outputs is likely to depend on an employee's intraorganisational social capital (Perry-Smith \& Shalley, 2003; Perry-Smith, 2006). Intraorganisational social capital is defined as the extent to which an employee has social ties within the social structure of a work unit, as well as in the broader social structure of the organisation to which the employee belongs, through which necessary resources can be accessed (Oh et al, 2004:861). Social embeddedness through social ties with colleagues can be an important precursor of individual creativity (Perry-Smith, 2006) as the extent to which employees connect with colleagues provides access to needed resources, reduces the need for monitoring (Oh et al., 2004), and serves as a sounding board for employees (Hanlon \& Saunders, 2007). In other words, social ties are channels for the transfer of resources such as materials, information, advice, evaluations, formal relations, etc. (Wasserman \& Faust, 2009) that could contribute to the generation of novel and useful ideas (Woodman et al., 1993).

In the definition of social capital by $\mathrm{Oh}$ et al. (2004), a distinction is drawn between an employee's social ties with colleagues within the same work unit and the broader social structure of the organisation. A similar distinction is drawn in this study because an employee's social embeddedness within the work unit or outside that work unit (but within the broader structure of the organisation) is expected to provide access to different types of knowledge resources and perform different functions in respect of creativity. That is, social ties with colleagues within the same work unit serve as a sounding board for employees (Hanlon \& Saunders, 2007), allowing them to ask for advice from colleagues who have domainrelevant knowledge (Perry-Smith \& Shalley, 2003). Amabile, Conti, Coon, Lazenby and Herron (1996) define domain-relevant knowledge as knowledge by a member of an organisation of facts, circumstances and issues surrounding a given work-related problem or area. It involves the expertise and experience that are necessary in order to come up with useful solutions to a given problem within the area. Having access to domain-relevant knowledge increases opportunities for employees to generate and validate useful ideas, products or services (Perry-Smith \& Shalley, 2003). Hence, social embeddedness within the work unit may enhance or deepen employees' understanding of the field of work. Through social ties employees may achieve creative outputs that they might not otherwise have been able to achieve (Sethia, 1995). We therefore hypothesise that:

Hypothesis 2a: The more employees are socially embedded within their work unit, the higher their creative output.

On the other hand, employees with social ties outside their work unit but within the same organisation are expected to have greater access to a more diverse set of resources (Pelled et al., 1999) as they act as brokers between intra- and interdepartmental networks. Social ties with colleagues outside the work unit can expand the diversity and currency of the knowledge and information available to an employee. Those employees who are more socially embedded outside their own work unit but within the organisation are more familiar with diverse, alternative ways of thinking, which increase the range of knowledge, skills and perspectives available to them (Pelled et al., 1999). In other words, employees who are socially embedded by virtue of the fact that they have many social ties with colleagues outside the work unit are expected to have greater access to a more diverse set of 
resources (Oh et al., 2004). Greater diversity of resources is likely to result in different perspectives and enhanced creativity in solving problems (Shalley \& Gilson, 2004). Furthermore, these ties could also allow employees to evaluate or discuss unconventional ideas with colleagues in different fields of expertise (Shalley \& Gilson, 2004). Social embeddedness through ties with colleagues outside the department is therefore considered a necessary precondition for the generation of novel and useful ideas or products (Amabile, 1988; Kanter, 1988; Woodman et al., 1993). Hence, we hypothesise that:

Hypothesis 2b: The more employees are socially embedded outside the work unit but within the organisation, the higher their creative output.

\subsection{The mediating role of social embeddedness}

Organisational culture refers to the taken-forgranted values, underlying assumptions, expectations, collective memories and definitions that provide unspoken guidelines on how to get along (Cameron \& Quinn, 1999). This is an important aspect of the organisational context that is likely to support the generation of novel and useful ideas by employees (Martins \& Terblanche, 2003). Besides the organisational culture, the extent to which employees are socially embedded by the number of social ties with colleagues is another aspect of the organisational context that affects the extent to which these employees generate creative output (Oh et al., 2004). However, since organisational culture is a frame of reference that provides norms for behaviour and activities in the organisation (O'Reilly et al., 1991; Khazanchi et al., 2007) it can also influence the extent to which employees forge social ties with colleagues and to which members of an organisation are willing to share knowledge and information. This in turn could affect an employee's creativity (Perry-Smith, 2006; Oh et al., 2004). Moreover, the extent to which employees are socially embedded by having ties with others can be a causal step in linking organisational values and norms to creative outputs.

Although literature on creativity assumes that both the organisational culture and social embeddedness are important for the generation of creative outputs (e.g. Amabile et al., 1996), studies ignore the relationship between organisational culture and social embeddedness (Drazin et al., 2008). However, as an organisational culture provides a frame of reference that guides employee behaviour (O'Reilly et al., 1991; Khazanchi et al., 2007) it could affect the extent to which employees generate novel and useful ideas as well as the extent to which they maintain social ties with colleagues within or outside the work unit. The latter, in turn, could also directly affect the generation of novel and useful ideas by employees (Perry-Smith \& Shalley, 2003). It therefore appears warranted to suggest that the relationship between organisational culture and creative output is mediated by the degree to which an employee is socially embedded by having social ties with colleagues within and outside his or her work unit. Amabile and colleagues (1996) underline this argument by stating that an organisational culture encourages creativity through the constructive evaluation of ideas and the active flow of information. Since the evaluation of ideas and the flow of information are resources transferred through social ties (Wasserman \& Faust, 2009), we hypothesise that:

Hypothesis 3: The degree to which employees are socially embedded by social ties (a) within their own work unit and (b) outside their unit (but within the organisation) mediates the relationship between the perceptions of organisational culture and creative output of these employees.

In sum, this study examines the extent to which perceptions of organisational culture affect the creative output as well as the social embeddedness of employees and, most importantly, it examines the extent to which the social embeddedness of employees mediates between perceptions of organisational culture and creative output. Figure 1 presents the research model for this study. 


\section{Figure 1}

Research model

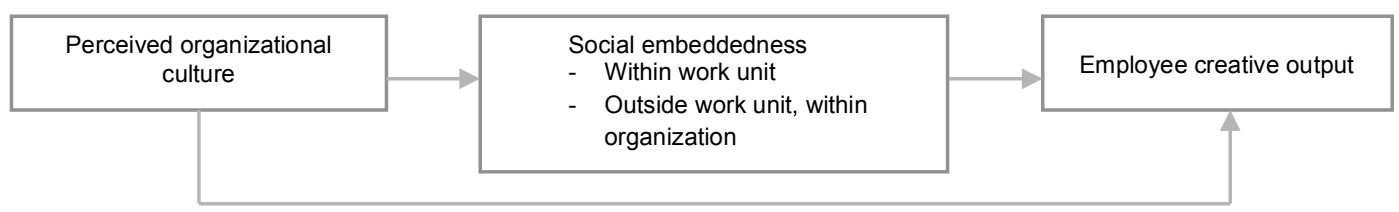

4

Methods

\subsection{Research setting}

Data were obtained from academics (assistant, associate and full professors) working at a school of social and behavioural sciences at a university in The Netherlands. According to Florida (2002), these academics belong to the "super creative core" and have in common a strong preference for being creative and working in a research environment in which creativity is valued and rewarded. In fact, these academics are likely to be involved in the highest order of creative work as they work solely on producing new ideas, forms or designs that are readily transferable and widely useful (Florida, 2002). Hence, we assume that academics in our sample will all be involved to some extent in the generation of creative outputs. In the engineering and technical sciences, creative output is predominantly embedded in patents. The creative ideas of social science scholars are in evidence at academic conferences and, more importantly, in peer-reviewed scholarly journals in which new theoretical and empirical ideas are judged by peers.

For the empirical analyses of this study, data were collected by means of a survey used for questioning scientists and university professors about the perceived organisational culture and the extent of their social ties. Based on documentation from the faculty's research institute, the survey was targeted at 131 academics. Of this number, six people had left the organisation. Hence, 125 scholars were invited to participate in this research by completing a survey. In total, 51 respondents (a response rate of $40.8 \%$ ) completed the survey in full.

\subsection{Measurement of the dependent variable}

The dependent variable in this study is creative output, which has a quantitative (number of outputs) and a qualitative (quality of outputs) component (Wierenga \& Van Bruggen, 1998). Regarding creative output, the assumption is that high-quality creative outputs of researchers and university professors are judged by and published in high-ranking, peer-reviewed journals. The more often a researcher produces journal articles that are published in highranking journals, the more creative that person's output is considered to be.

Reiter-Palmon, Robinson-Morral, Kaufman and Santo (2012) have studied the correlation between self-perceptions and objective measures of creativity. They found that as the measure of creativity becomes more objective the relation to self-perceptions of creativity becomes weaker; they conclude that objective measures of creative performance are favoured and caution is necessary when using self-perceptions of creative performance. This study therefore uses an objective and independently measured indicator of creative output which captures both the quality and the quantity of creative scientific output. That is, a variable is used that takes into account the number of times a person has been the (co)author of an article published in an ISI-ranked journal. Researchers' publications in the years 2010 and 2011 are included. In so doing, this study considers the time that elapsed between the researcher's initial ideas and the date of publication. In other words, there is a considerable time lag between the dependent and independent variables (see below). Furthermore, this way of measuring the dependent variable ensures that common method bias problems are kept to a minimum. 
The impact factors of the journals in which their articles were published are considered in addition to the number of publications by researchers. An impact factor (IF) of an academic journal is a variable reflecting the average number of citations in papers published in (social science) journals that are indexed in Thomson Reuters journal citation reports. The IF is frequently used as a proxy for the relative importance of a journal within a field of scholarship, with journals with higher impact factors being deemed to be more important than those with lower ones. Journals with higher impact factors are considered to publish papers that are regarded by other academics as more creative and innovative. The impact factor was devised by the Institute for Scientific Information (ISI), now part of Thomson Reuters.

The variable creative output is computed by adding up the IFs of the journals in which the papers of a respondent are published, and dividing this by the total number of published papers. This may be referred to as a respondent's "mean IF of publications". However, since IFs are not standardised across research fields, the creative output variable was controlled for the field of research in which respondents publish. To do this, we made an inventory of the research field to which the journal publications of each respondent relate. The ISI database gives the mean IF of publications for each research field. Per respondent, we multiplied the number of publications in each research field by the mean IF of that research field (as indicated in the ISI list). These IFs were totalled to give us a sum score of IFs of research fields per respondent. This score was divided by the number of publications and is referred to as the "mean IF of all research fields" in which a respondent published an article. Next, the respondent's "mean IF of publications" was divided by this "mean IF of all research fields", thereby producing the "controlled mean IF of publications" of that respondent. Finally, this controlled mean IF of publications was multiplied by the total number of publications by that respondent. The results of these calculations are the respondents' scores on the creative output variable, and capture the qualitative (IF of journal publications) and quantitative (number of publications) components of creative output while controlling for research fields. Thus, a researcher who achieves a high score on creative output would be someone who (co)produces many papers in high-ranking journals. For ease of clarification, an example of these steps in calculating the creative output variable is given in appendix 1.

Although we use the objective measure for creative output as described above, we check for response bias within the sample - that is, respondents answering questions in the way they think the questioner wants them to answer rather than according to their own beliefs (Easterby-Smith, Thorpe, Jackson \& Lowe, $2008)$ - to test whether the mean number of publications in the first quartile (the first $25 \%$ of respondents who returned the questionnaire) is significantly higher than in the last quartile (the last $25 \%$ of respondents who returned the questionnaire). A Mann-Whitney Test for testing the equality of two independent samples shows no statistically significant difference $(p=$ 0.775 ) between people in these two quartiles, which supports the nonexistence of response bias.

\subsection{Measurement of the independent variable}

Organisational culture is measured by means of 19 items, which capture the variety of takenfor-granted values, underlying assumptions and expectations that exist in the organisation. Items included in this study are based on Kivimäki and Elovainio's (1999) validated short version of the Team Climate Inventory (TCI), originally developed by Anderson and West (1998). For the purposes of this study, all items are adjusted to the organisational level, and measure the extent to which (1) having clear and realistic objectives, (2) member participation in a nonthreatening environment, (3) commitment to high-quality performance and appraisal of weaknesses, and/or (4) support for innovation are valued within the organisation. Furthermore, three items measure the extent to which awareness of and adaptability towards the organisation's external environment is valued. These items are based on Fey and Denison's (2003) customer focus scale, and are included to measure the environmental orientation dimension of organisational culture. On a fivepoint Likert scale, scientists and university 
professors were asked to what extent they perceived these statements as reflecting values at their university.

Exploratory factor analysis was performed on the 19 items measuring the organisational culture dimensions. Results indicate a fourfactor solution with sample adequacy (KaiserMeyer-Olkin measure $=0.837$ and Bartlett's Test of Sphericity $=0.000$ ). The four-factor solution is presented in table 1 , which displays inconclusive results for 2 items. Factor loadings for the item "people within my organisation build upon each other's ideas in order to achieve the best possible outcome" were too low (below 0.35). The item "within my organisation people feel understood and accepted by each other" received two fairly equal factor loadings. Allocation of these two items to any of the four factors would be inaccurate. Hence, these items with inconclusive results were excluded from the organisational culture measurement scale. The remaining 17 items clearly relate (more strongly) to one of the four factors representing organisational culture dimensions.

Table 1

Factor loadings of items measuring organizational culture dimensions.

\begin{tabular}{|c|c|c|c|c|}
\hline & \\
\hline & Factor 1 & Factor 2 & Factor 3 & Factor 4 \\
\hline $\begin{array}{l}\text { In order to achieve the best possible outcome, the people within my organization } \\
\text { critically appraise potential weaknesses in what they are doing. }\end{array}$ & 0.838 & & & \\
\hline $\begin{array}{l}\text { People within my organization are prepared to question the core of what they } \\
\text { are doing. }\end{array}$ & 0.736 & & & \\
\hline $\begin{array}{l}\text { Within my organization it is common to keep each other informed about the } \\
\text { work-related problems at hand. }\end{array}$ & 0.710 & & & -0.381 \\
\hline $\begin{array}{l}\text { People within my organization provide helpful advice and constructive feedback } \\
\text { in order to encourage me to achieve the best possible outcome }\end{array}$ & 0.640 & & & \\
\hline $\begin{array}{l}\text { Within my organization the commonly shared thought is that cooperation is } \\
\text { needed in order to get the work done. }\end{array}$ & 0.614 & & & \\
\hline $\begin{array}{l}\text { Within my organization people continuously try to share information with each } \\
\text { other. }\end{array}$ & 0.563 & & & \\
\hline The objectives of my organization are known by its members. & & 0.903 & & \\
\hline The objectives of my organization are understood by its members. & & 0.874 & & \\
\hline The objectives of my organization can actually be achieved. & & 0.723 & & \\
\hline The objectives of my organization are worthwhile. & & 0.721 & & \\
\hline The objectives of my organization are supported by all of its members. & & 0.710 & & \\
\hline Within my organization people feel understood and accepted by each other & 0.490 & -0.528 & & \\
\hline $\begin{array}{l}\text { Within my organization, comments and recommendations from other } \\
\text { departments, government, or society are often used to bring about change. }\end{array}$ & & & 0.807 & \\
\hline $\begin{array}{l}\text { Within my organization, adaptive ways are created to meet the changing needs } \\
\text { of government, society, or other stakeholders. }\end{array}$ & & & 0.755 & \\
\hline $\begin{array}{l}\text { Products or services delivered by my organization are primarily based on } \\
\text { information coming from fellow researchers, government, or other stakeholders. }\end{array}$ & & & 0.681 & 0.587 \\
\hline $\begin{array}{l}\text { Within my organization people search for fresh, new ways of dealing with } \\
\text { problems. }\end{array}$ & & -0.357 & 0.417 & \\
\hline Within my organization people can take the time needed to develop new ideas. & & & & 0.630 \\
\hline $\begin{array}{l}\text { Within my organization people cooperate in order to help develop and apply new } \\
\text { ideas. }\end{array}$ & & & & 0.607 \\
\hline $\begin{array}{l}\text { People within my organization build upon each other's ideas in order to achieve } \\
\text { the best possible outcome }\end{array}$ & & & & \\
\hline
\end{tabular}

Note: The four-factor solution with Oblimin rotation are reported because this resulted in the lowest number of double loaded items, and items with too low factor loadings (with values <.35 being suppressed).

Based on Comrey and Lee's (1992) argument, we only use items with "fair" to "excellent" factor loadings above .45 for interpretation. From the factor solution presented in table 1, we can deduce that six items with factor loadings above .45 relate to maximising the quality of task performance through critical appraisal, information sharing or cooperation. 
A new label was introduced for this dimension, namely performance orientation (factor 1). Items loading on this factor stem from the initial task orientation and participative safety dimensions of the TCI. In addition, factors 2 and 4 respectively capture the vision and innovation support dimensions of the TCI. Here, factor 2 consists of five items that are concerned with the clarity and degree of sharing of the vision and objectives of the organisation. Furthermore, two items concern the support of attempts to develop new and improved ways of doing things (factor 4). Lastly, three items were composed to measure the environmental orientation dimension of organisational culture. All three items have loadings above .45 on this environmental orientation dimension (factor 3 ), and jointly capture the organisation's sensitivity towards stakeholder needs and way of coping with these needs.

Reliability analysis was conducted to evaluate the internal consistency of the four dimensions of organisational culture, resulting in Cronbach's alphas as presented in table 2. For the environmental orientation dimension, the reported value is the Cronbach's alpha after deletion of the item "within my department, adaptive ways are created to meet the changing needs of customers, suppliers, government, or other stakeholders" (deletion led to improvement from 0.678 to 0.746 ). Alphas for the performance orientation, vision orientation and environmental orientation scales are well above the generally accepted rule of thumb of alpha $>0.70$ (Nunnally, 1978). Moreover, since the Cronbach's alpha for innovation support is almost equal to 0.70 , all measurement scales of the organisational culture dimensions are considered internally consistent in this study.

Table 2

Organizational culture dimensions and alphas

\begin{tabular}{|l|c|}
\hline \multicolumn{1}{|c|}{ Factor } & Cronbach's Alpha \\
\hline 1 Performance orientation & 0.858 \\
\hline 2 Vision & 0.868 \\
\hline 3 Environmental orientation & 0.746 \\
\hline 4 Innovation support & 0.692 \\
\hline
\end{tabular}

\subsection{Measurement of mediator variables}

The mediator variables used in this study are social embeddedness (number of ties) within the department, or outside the department but within the organisation. In this research, the university department for which researchers mostly work is considered to be the department they are part of. Social embeddedness within the department captures the extent to which employees have direct ties with colleagues working in the same department. Social embeddedness outside the department deals with the extent to which employees have direct ties with colleagues working in a different department, but within the same university. Such ties are channels for the transfer of resources such as materials, information or advice, evaluations, formal relations, etc. (Wasserman \& Faust, 2009). As Amabile and Mueller (2008) state that gathering information and evaluating ideas with colleagues play an important role in the process of generating creative outputs, the resources used in this study are the extent to which ideas are evaluated, as well as the extent to which information or advice is gathered by employees through ties with colleagues either within or outside their department.

For the purposes of this study it is important to note that there is a time lag between the gathering of information by researchers, using social ties to gather information or discuss ideas, and the actual generation of creative output in the form of published journal articles. That is, a researcher's novel ideas are likely to have emerged some time before these ideas are actually published in journal articles. This study takes note of this time lag and therefore invites respondents in mid-2010 to report on the number of ties they had in the past year. Data on the social embeddedness of employees therefore refer to the period from mid-2009 to mid-2010. As stated above, creative output was measured by researchers' publications in 
the years 2010 (in total) and 2011. This study considers the time lag between the development of ideas and creative output.

The mediator variable "social embeddedness within department" is measured by two items. The first item is "throughout last year, which researchers from your department did you contact in order to obtain information or advice concerning research-related matters?" These ties are channels for gathering information and advice from researchers working within the respondent's own department. The second item is "throughout last year, which researchers from your department did you contact in order to discuss or evaluate new ideas, or possible solutions to research-related problems?" These ties particularly focus on the discussion and evaluation of new ideas or solutions with researchers working within the respondent's own department. Both items capture the social ties that existed between mid-2009 and mid-2010. Since all members of the departments were known in advance, a roster was constructed in which all the researchers working within the respondent's department were listed. Each respondent was asked to answer the questions by ticking the box of persons to which each question applied. Respondents were not given any constraints on how many colleagues they could select.

Similar to social embeddedness within the department, the "social embeddedness outside department but within organisation" variable was measured by means of two items. The first item is "throughout last year, which researchers from outside your department did you contact in order to obtain information or advice concerning research-related matters?" These ties are channels for gathering information and advice from researchers working outside the respondent's own department. The second item is "throughout last year, which researchers from outside your department did you contact in order to discuss or evaluate new ideas, or possible solutions to research-related problems?" These ties focus on the discussion and evaluation of new ideas or solutions with researchers working outside the respondent's own department. Again, both items capture the social ties that existed between mid-2009 and mid-2010. In an introduction to each question it is clearly stated that the question concerns the contact a respondent has had with researchers from other departments within the same university. Since not all the names of researchers outside the department were known in advance, no roster could be constructed. Hence, respondents were asked to list the last names and schools (e.g. the school of law) of researchers outside their department to whom these questions applied.

Exploratory factor analysis was performed on the four items measuring the two mediator variables (see table 3), resulting in a two-factor solution with a Kaiser-Meyer-Olkin measure $(\mathrm{KMO}=0.584)$ above the acceptable limit of .50 (Field, 2009) and a significance of Bartlett's Test of Sphericity $(\mathrm{p}=0.000)$ indicating sample adequacy. Reliability analysis was conducted on the measurement scales of social ties within and outside the department, resulting in Cronbach's alphas of 0.758 and 0.872 respectively, which is above the generally accepted rule of thumb of alpha $>0.70$ (Nunnally, 1978). Thus, both the number of social ties within the department (factor 1) and the number of social ties outside the department (factor 2) are internally consistent as measured by means of the two items presented in table 1 . As an aid to interpretation, in further analysis we use the raw scores of individuals on social ties within and outside the department. In other words, the number of social ties (within and outside) is calculated as the sum score of the two items involved.

\section{5}

\section{Mediated regression approach}

The mediated regression approach as proposed by Baron and Kenny (1986) was used in this study to test the research model presented in figure 1. Following this approach, four separate regression analyses were performed in different steps. In the first step, the dependent variable (i.e. creative output) was regressed on the independent variable (i.e. organisational culture). In the second step, creative output was simultaneously regressed on social embeddedness within, and social embeddedness outside the department. In the third step, the mediator variable was regressed on the independent variable. Since two different mediator variables are included in this study, the variable social embeddedness within the department was first regressed on organisational culture, before social 
embeddedness outside the department was regressed on it. In the fourth step, creative output was simultaneously regressed on organisational culture and social embeddedness within the department. The same was done for social embeddedness outside the department in a separate regression model.

Table 3

Factor loadings of items measuring social ties within the department (factor 1), and social ties outside the department (factor 2)

\begin{tabular}{|l|c|c|}
\hline \multicolumn{1}{|c|}{ Item } & Factor $\mathbf{1}$ & Factor $\mathbf{2}$ \\
\hline $\begin{array}{l}\text { Throughout last year, which researchers from your department did you contact in order to } \\
\text { discuss or evaluate new ideas, or possible solutions to research-related problems? }\end{array}$ & .952 & \\
\hline $\begin{array}{l}\text { Throughout last year, which researchers from your department did you contact in order to } \\
\text { obtain information or advice concerning research-related matters }\end{array}$ & .899 & \\
\hline $\begin{array}{l}\text { Throughout last year, which researchers from outside your department did you contact in order } \\
\text { to obtain information or advice concerning research-related matters? }\end{array}$ & .902 \\
\hline $\begin{array}{l}\text { Throughout last year, which researchers from outside your department did you contact in order } \\
\text { to discuss or evaluate new ideas, or possible solutions to research-related problems? }\end{array}$ & .875 \\
\hline
\end{tabular}

Note 1: Varimax rotated factor loadings rotation are reported with values $<.35$ being suppressed

According to Baron and Kenny (1986), a variable is a mediator when the independent variable affects the dependent variable in step 1 , the mediator variable affects the dependent variable in step 2 and the independent variable affects the mediator variable in step 3 . In addition, the previously statistically significant effects between independent variables and the dependent variable (step 1) must be no longer, or less significant in step 4.

Perfect mediation is present if the independent variable has no statistically significant effect on the dependent variable when controlled for the mediator variable. Partial mediation occurs if the effect of the independent variable is reduced in magnitude when controlled for the mediator variable. However, as the independent variable is assumed to cause the mediator (step 3 ), multicollinearity may be found to occur when the effects of the independent and mediator variables on the dependent variable are simultaneously estimated. Baron and Kenny (1986) say that this may reduce the power of the test of coefficients in step 4. Hence, in the last step to determine whether partial mediation is present, it is important to examine not only the significance of the coefficients but also the absolute size of effects.

\section{6}

\section{Results}

The initial findings of the data analysis show that the distribution of creative output by respondents is positively skewed (with Mean = $8,98$; S.D. $=11,40)$. This skewness is not surprising as scores on the creative output variable could not go below 0 . With regard to positively skewed data and the normal distribution assumption in regression analysis, Tabachnick and Fidell (2001) state that a common procedure is to transform data using logarithms and improve distributional assumptions. More particularly, in the case of substantial positive skewness, Log10 transformations are recommended (Tabachnick \& Fidell, 2001), and were therefore composed for the dependent variable in this study. Table 4 reports means, standard deviations and Pearson correlations for this and all other variables. Furthermore, Variance Inflation Factors (VIFs) were obtained to check for multicollinearity between variables. In the model with social embeddedness within the department (step 4a of table 5), the highest Variance Inflation Factor (VIF) value was 2,230, which is well below the critical value of 10 (Pallant, 2005). In the model with social embeddedness outside the department (step 3b of table 5), the highest VIF was 2.694. These VIF values confirm that multicollinearity is not a problem in the models.

Table 5 contains the results of the mediated regression analyses. In step 1, the results for the relationships between organisational culture dimensions and creative output are presented. Hypothesis 1 proposes positive linear relationships between each of the dimensions of 
organisational culture and creative output. Step 1 shows nonsignificant findings for the F-test, however, in that all the coefficients are $0(\mathrm{~F}=$ $1.026 ; \mathrm{p}=.407)$. If the F-test for all the variables in a multiple regression model is nonsignificant, one should be extremely cautious about drawing conclusions about the variables and their effects (Allison, 1999). Hence, as results from the model presented in step 1 of table 5 provide no evidence for a direct linear relationship between organisational culture dimensions and creative output, hypothesis 1 is rejected.

Table 4

Descriptive statistics and inter-correlations for all variables in study $(n=51)$

\begin{tabular}{|c|c|c|c|c|c|c|c|c|c|}
\hline \multicolumn{2}{|r|}{ Variables } & Mean & SD & 1. & 2. & 3. & 4. & 5. & 6. \\
\hline 1 & $\begin{array}{l}\text { Creative output (log) } \\
\text { Organizational culture }\end{array}$ & 0.795 & 0.407 & & & & & & \\
\hline 2 & Performance orientation & 3.571 & 0.675 & 0.124 & & & & & \\
\hline 3 & Vision orientation & 2.275 & 0.669 & -0.124 & $-0.500^{* *}$ & & & & \\
\hline 4 & Environmental orientation & 3.183 & 0.630 & -0.023 & $0.386^{* *}$ & $-0.378^{* *}$ & & & \\
\hline 5 & Innovation support & 3.735 & 0.710 & $0.235^{\star}$ & $0.697^{\star *}$ & $-0.438^{* *}$ & $0.319^{* *}$ & & \\
\hline 6 & $\begin{array}{l}\text { Social embeddedness within } \\
\text { department }\end{array}$ & 21.059 & 11.404 & $0.276^{\star *}$ & $0.390^{* *}$ & $-0.374^{\star *}$ & 0.227 & $0.389^{* *}$ & \\
\hline 7 & $\begin{array}{l}\text { Social embeddedness outside } \\
\text { department }\end{array}$ & 7.333 & 7.397 & $0.342^{\star *}$ & -0.098 & -0.114 & $0.257^{*}$ & 0.209 & 0.255 \\
\hline
\end{tabular}

Note: ${ }^{*} p<0.10,{ }^{* *} p<0.05$

Table 5

Results of mediated regression analyses

\begin{tabular}{|c|c|c|c|c|c|}
\hline Step & Model & Independent variables in model & Beta & Significance & Dependent variable in model \\
\hline 1 & $\begin{array}{l}\mathrm{R}^{2}=.100 \\
\mathrm{~F}=1.026\end{array}$ & $\begin{array}{l}\text { Organizational culture } \\
\text { Performance orientation } \\
\text { Vision orientation } \\
\text { Environmental orientation } \\
\text { Innovation support }\end{array}$ & $\begin{array}{r}-.276 \\
-.095 \\
-.046 \\
.394\end{array}$ & $\begin{array}{l}.238 \\
.606 \\
.800 \\
.067^{\star}\end{array}$ & Creative output \\
\hline 2 & $\begin{array}{l}\mathrm{R}^{2}=.134 \\
\mathrm{~F}=3.015^{\star}\end{array}$ & $\begin{array}{l}\text { Social embeddedness within department } \\
\text { Social embeddedness outside department }\end{array}$ & $\begin{array}{l}.133 \\
.309\end{array}$ & $\begin{array}{l}.392 \\
.052^{*}\end{array}$ & Creative output \\
\hline $3 a$ & $\begin{array}{l}\mathrm{R}^{2}=.214 \\
\mathrm{~F}=3.126^{\star *}\end{array}$ & $\begin{array}{l}\text { Organizational culture } \\
\text { Performance orientation } \\
\text { Vision orientation } \\
\text { Environmental orientation } \\
\text { Innovation support }\end{array}$ & $\begin{array}{r}.142 \\
-.208 \\
.033 \\
.188\end{array}$ & $\begin{array}{l}.468 \\
.191 \\
.820 \\
.313\end{array}$ & $\begin{array}{l}\text { Social embeddedness within } \\
\text { department }\end{array}$ \\
\hline $3 b$ & $\begin{array}{l}\mathrm{R}^{2}=.260 \\
\mathrm{~F}=3.257^{\star *}\end{array}$ & $\begin{array}{l}\text { Organizational culture } \\
\text { Performance orientation } \\
\text { Vision orientation } \\
\text { Environmental orientation } \\
\text { Innovation support }\end{array}$ & $\begin{array}{r}-.621 \\
-.101 \\
.363 \\
.453\end{array}$ & $\begin{array}{l}.005^{\star \star \star} \\
.545 \\
.033^{\star \star} \\
.022^{\star *}\end{array}$ & $\begin{array}{l}\text { Social embeddedness outside } \\
\text { department }\end{array}$ \\
\hline $4 a$ & $\begin{array}{l}R^{2}=.116 \\
F=1.185\end{array}$ & $\begin{array}{l}\text { Social embeddedness within department } \\
\text { Organizational culture } \\
\text { Performance orientation } \\
\text { Vision orientation } \\
\text { Environmental orientation } \\
\text { Innovation support }\end{array}$ & $\begin{array}{r}.240 \\
-.103 \\
-.028 \\
-.126 \\
.241\end{array}$ & $\begin{array}{l}.136 \\
.625 \\
.871 \\
.426 \\
.234\end{array}$ & Creative output \\
\hline $4 b$ & $\begin{array}{l}R^{2}=.174 \\
F=1.516\end{array}$ & $\begin{array}{l}\text { Social embeddedness outside department } \\
\text { Organizational culture } \\
\text { Performance orientation } \\
\text { Vision orientation } \\
\text { Environmental orientation } \\
\text { Innovation support }\end{array}$ & $\begin{array}{r}.317 \\
-.079 \\
-.063 \\
-.161 \\
.251\end{array}$ & $\begin{array}{l}.081^{*} \\
.752 \\
.725 \\
.395 \\
.257\end{array}$ & Creative output \\
\hline
\end{tabular}

Notes: ${ }^{*} p<0.10,{ }^{* *} p<0.05,{ }^{* * *} p<0.01$

Models 3a \& 4 a include the mediator variable 'social embeddedness within department'

Models $3 b$ \& $4 b$ include the mediator variable 'social embeddedness outside department'. 
Hypothesis 2a concerns the direct relationship between employees' social embeddedness within the department and creative output. Following Cohen's (1988) guidelines, table 4 shows that there is only a small positive correlation $(\mathrm{r}=$ .276) between the two variables. Step 2 of table 5, however, shows a statistically nonsignificant effect of social embeddedness within the department on creative output $(\beta=$ $.133 ; \mathrm{p}=.392$ ) in a model that includes employees' social embeddedness outside the department. Findings from this model lead to the rejection of hypothesis $2 \mathrm{a}$.

With regard to employees' social embeddedness outside the department, the results shown in table 4 show a moderate and positive correlation $(\mathrm{r}=.342)$ with creative output. In step 2 of table 5 , this relationship between employees' social embeddedness outside the department and creative output (hypothesis 2b) is tested in a model that includes employees' social embeddedness within the department. Results obtained in this step reveal a positive and statistically significant relationship between social embeddedness outside the department and creative output $(\beta=.309 ; p=.052)$. This finding confirms hypothesis $2 \mathrm{~b}$.

In order to test for mediation, Baron and Kenny (1986) state that the first step is to regress the dependent variable creative output on the independent variable organisational culture. Results for this step come from the model presented in step 1 of table 5. Yet, as discussed above, this model presents statistically nonsignificant findings for the F-test in that all the coefficients were found to be 0 . Similar nonsignificant F-tests were found for models presented in steps $4 \mathrm{a}$ and $4 \mathrm{~b}$. Results from these models provide no evidence for a direct linear effect of social embeddedness (within or outside the department, respectively) and organisational culture dimensions on creative output. As no mediating effects were found, hypotheses $3 \mathrm{a}$ and $3 \mathrm{~b}$ are both rejected. However, as it is argued in this study that organisational culture is a frame of reference that provides norms for behaviour and activities within the organisation (O'Reilly et al., 1991; Khazanchi et al., 2007), this could influence the extent to which employees develop social ties with colleagues, which may, in turn, affect an employee's creativity
(Perry-Smith, 2006; Oh et al., 2004). Although the results given in table 5 show that no mediation effects exist, the extent to which employees are socially embedded by having ties with others is still considered to be a causal step linking organisational values and norms to creative outputs. Consequently, this study tested for the presence of an indirect effect of organisational culture dimensions on creative output through employees' social embeddedness within or outside the department instead.

In order to demonstrate the existence of an indirect effect, results must show a statistically significant effect of at least one organisational culture dimension on employees' social embeddedness outside the department, which in turn has a statistically significant effect on their creative output. Yet, as discussed above, step 2 of table 5 reports statistically nonsignificant findings for the relationship between social embeddedness within the department and creative output $(\beta=.133 ; p=.392)$. Furthermore, results in step $3 \mathrm{a}$ of table 5 show statistically nonsignificant effects of all four organisational culture dimensions on social embeddedness within the department (performance orientation; $\beta=.142 ; \mathrm{p}=.468$; vision orientation; $\beta=$ $.208 ; \mathrm{p}=.191$; environmental orientation; $\beta=$ $.033 ; \mathrm{p}=.820$; innovation support; $\beta=.188 ; \mathrm{p}$ $=.313$ ). From this we can conclude that organisational culture has no indirect effect on creative output through employees' social embeddedness within the department.

In contrast, findings in step 2 of table 5 report a statistically significant relationship between social embeddedness outside the department and creative output $(\beta=.309 ; \mathrm{p}=$ $.052)$. Moreover, results in step $3 \mathrm{~b}$ show a statistically significant negative effect of performance orientation $(\beta=-.621 ; \mathrm{p}=.005)$, as well as statistically significant positive effects of environmental orientation $(\beta=.363$; $\mathrm{p}=.033)$ and innovation support $(\beta=.453 ; \mathrm{p}=$ .022 ) on social embeddedness outside the department. For vision orientation, nonsignificant findings were reported $(\beta=-.101 ; p=.545)$. These findings suggest that three organisational culture dimensions - i.e. performance orientation (negative), environmental orientation and innovation support (positive) - have an indirect effect on creative output through employees' 
social embeddedness outside the department.

Finding a negative relationship between performance orientation and social embeddedness outside the department is somewhat remarkable as this dimension is composed of items measuring the initial TCI dimensions "task orientation" and "participative safety" (see results from exploratory factor analysis in table 1). It raises the question whether there is a particular aspect of the performance orientation dimensions that contributes negatively to this social embeddedness. In search of an explanation for these findings, Pearson correlations between every single item of performance orientation and social embeddedness outside the department were computed. From this analysis, it appears that the item "In order to achieve the best possible outcome, the people within my organisation critically appraise potential weaknesses in what they are doing" $(\mathrm{r}=-.270 ; \mathrm{p}=$ $.084)$ is negatively correlated with social embeddedness outside the department. Moreover, this item turns out to be the only item that has a statistically significant correlation with social embeddedness outside the department (at $\alpha<$
.10). These findings indicate that employees would have fewer social ties outside their department if they perceived that critical appraisal was strongly valued in the organisation.

\section{7}

\section{Discussion}

This study has focused on the impact of two contextual aspects on individual creative output. The purpose of the study was to examine the extent to which employees' perceptions of organisational culture affect their creative output as well as social embeddedness and, most importantly, to what extent the social embeddedness of employees mediates between perceptions of organisational culture and creative output. More broadly, this study extends the discussion on the antecedents of creativity by focusing on two dimensions of the context in which the individual is embedded. Findings in this study are reflected in the final model, which is presented in figure 2.

Figure 2

Final model

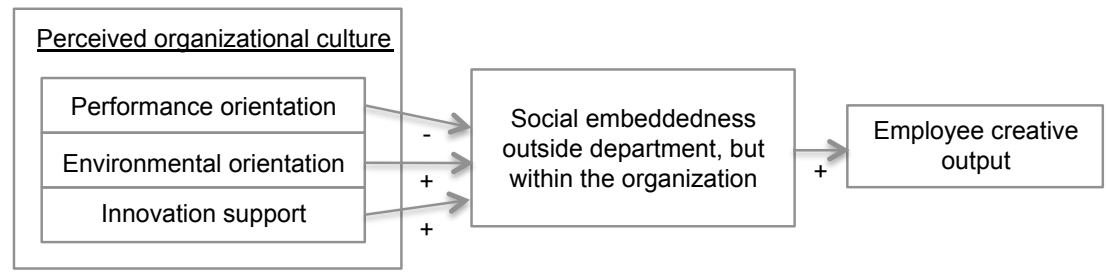

Empirical findings of this study have demonstrated that researchers' social embeddedness outside the department but within the organisation contributes to their creative output. A researcher with many social ties outside the department is likely to have better access to diverse resources (Oh et al., 2004), which increases the range of knowledge, skills and perspectives available to that employee (Pelled et al., 1999). Social embeddedness outside the department therefore provides a greater variety of information and gives employees a competitive advantage in seeing and generating novel and useful outputs (Burt, 2005). However, it has been argued in this study that the extent to which employees are socially embedded by having social ties with others is a causal step linking organisational values and norms to creative outputs. This study did not find support for the proposed mediating effects, but found instead that three dimensions of organisational culture - i.e. performance orientation, environmental orientation and innovation support affect employees' creative output through their social embeddedness outside the department (but within the organisation). Hence, as organisational culture and the social embeddedness of employees outside the department are both contextual factors that are of significance (either indirectly or directly) in the generation 
of creative outputs by scholars, this study argues that "no creative person is an island".

With regard to performance orientation, findings suggest that if an organisational culture is perceived as being strongly performance oriented, employees working in that environment have fewer social ties with colleagues outside their department and, consequently, generate less creative output. At the item level it has been shown that this negative relationship is caused by the item that measures performance orientation. This item particularly concerns the critical appraisal of potential weaknesses. The explanation advanced by this study for the negative correlation of this item with social embeddedness outside the department is that if employees pay too much attention to potential weaknesses or limitations of ideas, they may be less socially embedded because they do not feel the need to gather more information to develop these ideas, or to discuss and evaluate ideas with others outside their department. Moreover, the (negative) indirect effect of performance orientation on creative output through social embeddedness outside the department provides evidence for Amabile and Mueller's (2008) statement that where harsh criticism of new ideas is the norm this can actually block the generation of creative outputs. In contrast, Isaksen and Lauer (2002) argue that actual support for ideas matters. They define idea support as the way new ideas are considered, taken up, and advocated by others. When idea support is high, employees listen to each other and support each other's ideas (Isaksen \& Lauer, 2002). In contrast, low idea support may hamper the extent to which employees support each other's new ideas. Findings in this study suggest that if employees constantly criticise each other's ideas, they will have fewer ties outside the department through which to gather diverse information, obtain advice or evaluate ideas. Hence we conclude that perceived performance orientation negatively influences an employee's creative output through that employee's social embeddedness outside the department.

The fact that idea support is important for the generation of creative output is endorsed by the findings for innovation support, the organisational culture dimension dealing with the extent to which support of attempts to develop new and improved ways of doing things is valued in the organisation (Anderson \& West, 1998). Findings in this study show that innovation support contributes to an employee's social embeddedness outside the department, eventually leading to higher creative output. That is, in an organisational culture characterised by strong support for innovation employees are likely to search for new ways of doing things, because that is what is actually valued by that organisation (Locke \& Kirkpatrick, 1995; West, 2002). In searching for new ways of doing things, employees become more socially embedded as they develop social ties with colleagues outside their department who provide them with access to diverse and new knowledge, skills, and perspectives (Pelled et al., 1999; Oh et al., 2004). In turn, social embeddedness outside the department contributes to the generation of novel and useful creative outputs. Hence, we conclude that perceived innovation support positively influences an employee's creative output through that employee's social embed-dedness outside the department.

Finally, findings in this study also show that an employee's social embeddedness outside the department is enhanced by a strong orientation towards the organisation's external environment. An organisational culture of this nature is characterised by a strong sensitivity towards changing external stakeholder needs (Kotter, 2008). From these findings we can conclude that, in organisational cultures in which sensitivity towards changes in the external environment is valued, employees are encouraged to form and maintain social ties with colleagues outside the department. That is, organisations characterised by a strong environmental orientation develop a sense of urgency about adapting their traditional working methods (Kotter, 2008), which motivates employees to get together and share knowledge in order to generate creative solutions that help to adapt to these changing needs (Ford \& Kuenzi, 2008). Moreover, Breu and Hemingway (2002) state that these cross-boundary ties are considered necessary in the creation of novel combinations of knowledge from the distinct competencies of employees and the colleagues with whom they interact. Hence, we conclude that an orientation towards the external environment positively influences an employee's creative 
output through that employee's social embeddedness outside the department.

\subsection{Implications for project-based productions}

As stated above, findings in this study suggest that performance orientation negatively affects the number of social ties academic researchers have with colleagues outside their department and that the consequence of this is reduced creative output. At the item level it has been shown that this negative relationship is caused by the critical appraisal of potential weaknesses. In an organisational culture characterised by the critical appraisal of potential weaknesses, people are intolerant of shortcomings or failures in work execution. As a result, and for the sake of avoiding negative feedback, employees form fewer social ties outside their department because they do not feel the need to gather more information to develop ideas, or to expose, discuss and evaluate those ideas with others outside their department. This consequently results in academic researchers' producing less creative project output. Academic researchers therefore become less productive in terms of the number of novel and useful ideas presented in published papers. Hence, the findings of this study suggest that organisational culture, as an incentive system in project-based productions, can affect employee productivity in particular, and project output in general. More particularly, the drawback of creativity in project-based productions may be that it competes with the importance accorded to organisational cultures that support the critical appraisal of potential weaknesses.

\subsection{Implications for future research}

This study used an objective measure of the dependent variable creative output, based on documentation from the faculty's research institute. For this variable both the impact factors (IFs) of journals in which respondents published and the number of published papers were taken into consideration. The IF is frequently used as a proxy for the relative importance of a journal within an academic field, with journals with higher impact factors deemed to be more important than those with lower ones. However, these IFs are not standardised across research fields. The distribu- tion of citations is very uneven, with a few publications getting many citations, and many papers only a few. In order to reduce the uneven distribution of IFs, this study controlled for the field of research in which respondents published (see appendix 1 for calculation). However, using a standardised measure or IFs from only one field of research would rule out the issue of uneven distributions.

Furthermore, this study addresses a potential causality issue in the relationship between organisational culture and social embeddedness. Although it is argued in this study that organisational culture is a frame of reference that provides norms for behaviour and activities (O’Reilly et al., 1991; Khazanchi et al., 2007) and, as such, influences the number of social ties employees have with colleagues, some researchers claim the opposite. Literature on socialisation argues that values and norms are communicated by employees, socialising them and shaping their behavior (Leana \& Van Buren, 1999). More specifically, Wuyts, Colombo, Dutta, \& Nooteboom (2005) state that social ties contribute to the establishment of similarities in the way employees perceive, interpret and understand their field of work. As this causality issue may thwart the interpretation of findings on this relationship, future research could examine whether organisational culture affects the number of social ties, or vice versa.

It should also be noted that this study tried to determine whether employees' social embeddedness through the number of social ties with colleagues within or outside the department mediates the relationship between organisational culture and creative output. Recent studies on the role of social ties in determining creativity also refer to the strength of these ties, however (Perry-Smith, 2006; Kratzer, Leenders \& Van Engelen, 2009). These studies argue that strong ties involve a high level of emotional closeness, relatively frequent contacts, and reciprocity, while weak ties involve low levels of emotional closeness and nonredundant contacts (Granovetter, 1973). In order to increase understanding of the indirect effect found in this study, future research may not only focus on the number of ties, but could also consider the extent to which the strength of the ties mediates the relationship between organisational culture and creative output. 
It is also worth mentioning that, regardless of the relatively small sample $(\mathrm{n}=51)$, this study has found evidence for a statistically significant, indirect effect of three dimension of organisational culture on creative output through the social embeddedness of employees outside their department. According to Allison (1999), statistically significant coefficients should be taken very seriously in studies with small samples. In contrast, this small sample size may be the key reason why nonsignificant F-tests were found for models $1,4 \mathrm{a}$ and $4 \mathrm{~b}$ in table 5. Based on these results, it is concluded that no mediating effects exist in this study. Nonsignificant tests are, however, weak evidence for the absence of an effect (Allison, 1999) in small sample studies. Hence, it is recommended that future studies examining the mediating role of social embeddedness in the relationship between organisational culture and creative output use a larger data set.

Finally, in view of the small sample size one could question the generalisability of findings from this study. This study has focused particularly on academics' creative project output. As stated above, one criterion for project-based productions relates to the singularity of projects, namely the extent to which projects focus on developing unusual, sometimes one-off, products or services (Whitley, 2006). In academic projects, this is manifestly present as paper productions commonly and explicitly state what the addressed knowledge gap is and what contribution the study will make to the research field. Producing these creative project outputs is the core of these academics' work. However, in business contexts, this may be less evident, as projects in firms with little environmental uncertainty (i.e. stable and predictable environments) have less need for innovation, and are therefore less likely to generate unique outputs (Miles, Covin \& Heeley, 2000). In contrast, project-based productions in knowledge-intensive, rapidly changing and unpredictable environments may comprise a high level of uniqueness as creativity is a key factor in innovation and long-term organisational survival (Mathisen et al., 2004). It can therefore be argued that findings from this study are generalisable to knowledgeintensive business contexts in which there is a need for creative outputs. Nevertheless, future research could further explore the relationships between organisational culture, social embeddedness and creative project output in business contexts.

\section{Endnote}

1 Amabile (1983) proposed a five stage model of the creative process. These five stages are (1) task presentation: the analysis and articulation of the exact nature of the problem to be solved, (2) preparation: the gathering of relevant information to solve the problem, (3) idea generation: the production of possible responses to the problem, (4) idea validation: checking and evaluating each idea for appropriateness, and (5) outcome assessment: choosing a new and useful solution (Shalley \& Zhou, 2008). These stages can follow the sequence as presented here, but may also recur iteratively until a creative output has been generated (Amabile \& Mueller, 2008).

\section{Acknowledgements}

We would like to thank Roger Schmitz for giving us access to publication data and Sanne Keurentjes for her research assistance. Of course, the usual disclaimers apply.

\section{References}

AGRELL, A. \& GUSTAFSON, R. 1994. The Team Climate Inventory (TCI) and group innovation: A psychometric test on a Swedish sample of work groups. Journal of Occupational and Organizational Psychology, 67:143-151.

AHMED, P.K. 1998. Culture and climate for innovation. European Journal of Innovation Management, 1:3043.

ALLISON, P.D. 1999. Multiple regression analysis: A primer. Thousand Oaks: Pine Forge Press.

AMABILE, T.M. 1983. The social psychology of creativity: A componential conceptualization. Journal of Personality and Social Psychology, 45:357-376.

AMABILE, T.M. 1988. A model of creativity and innovation in organizations. In: B.M. Staw \& L.L. Cummings (eds.) Research in organizational behavior. Greenwich: JAI Press. 
AMABILE, T.M., CONTI, R., COON, H., LAZENBY, J. \& HERRON, M. 1996. Assessing the work environment for creativity. Academy of Management Journal, 39: 1154-1184.

AMABILE, T.M. \& MUELLER, J.S. 2008. Studying creativity, its processes, and its antecedents: An exploration of the componential theory of creativity. In J. Zhou \& C. E. Shalley (eds.) Handbook of organizational creativity (pp. 123-167). New York: Erlbaum.

ANDERSON, N.R. \& WEST, M.A. 1998. Measuring climate for work group innovation: Development and validation of the team climate inventory. Journal of Organizational Behavior, 19:235-258.

ANDRIOPOULOS, C. 2001. Determinants of organizational creativity: A literature review. Management Decision, 39:834-841.

BARON, R.M. \& KENNY, D.A. 1986. The moderator-mediator variable distinction in social psychological research: Conceptual, strategic, and statistical considerations. Journal of Personality and Social Psychology, 51:1173-1182.

BREU, K. \& HEMINGWAY, C. 2002. Collaborative processes and knowledge creation in communities-ofpractice. Creativity and Innovation Management, 13:30-40.

BURT, R.S. 2005. Brokerage and closure: An introduction to social capital. New York: Oxford University Press.

CAMERON, K.S. \& QUINN, R.E. 1999. Diagnosing and changing organizational culture. San Fransisco: Jossey-Bass.

CASPER, S. \& WHITLEY, R. 2004. Managing competences in entrepreneurial technology firms: A comparative institutional analysis of Germany, Sweden and the UK. Research Policy, 33:89-106.

CHRISTOPHERSON, S. \& VAN JAARSVELD, D. 2005. New media after the dot.com burst. International Journal of Cultural Policy, 11:77-93.

COHEN, J. 1988. Statistical power analysis for the behavioral sciences. Hillsdale: Erlbaum.

COMREY, A.L. \& LEE, H.B. 1992. A first course in factor analysis $\left(2^{\text {nd }}\right.$ ed.) Hillsdale: Erlbaum.

CUMMINGS, A. \& OLDHAM, G.R. 1997. Enhancing creativity: Managing work contexts for the high potential employee. California Management Review, 40:22-38.

DE BRENTANI, U. \& KLEINSCHMIDT, E.J. 2004. Corporate culture and commitment: Impact of performance of international new product development programs. Journal of Product Innovation Management, 21:309-333.

DENISON, D.R. 1996. What is the difference between organizational culture and organizational climate? A narrative's point of view on a decade of paradigm wars. Academy of Management Review, 21:619-654.

DESHPANDÉ, R., FARLEY, J.U. \& WEBSTER, F.E. 1993. Corporate culture, customer orientation, and innovativeness in Japanese firms: A quadrad analysis. Journal of Marketing, 57:23-37.

DILIELLO, T.C. \& HOUGHTON, J. D. 2006. Maximizing organizational leadership capacity for the future. Journal of Managerial Psychology, 21:319-337.

DOMBROWSKI, C., KIM, J.Y., DESOUZA, K. C., BRAGANZA, A., PAPAGARI, S., BALOH, P. \& J.H.A., S. 2007. Elements of innovative cultures. Knowledge and Process Management, 14:190-202.

DRAZIN, R., KAZANJIAN, R. \& GLYNN, M. 2008. Creativity and sensemaking among professionals. In J. Zhou \& C. E. Shalley (eds.) Handbook of organizational creativity (pp. 263-282). New York: Erlbaum.

EASTERBY-SMITH, M., THORPE, R., JACKSON, P.R. \& LOWE, A. 2008. Management research (3 ${ }^{\text {rd }}$ ed.) London: Sage.

EKVALL, G. 1996. Organizational climate for creativity and innovation. European Journal of Work and Organizational Psychology, 5:105-123.

FEY, C.F. \& DENISON, D.R. 2003. Organizational culture and effectiveness: Can American theory be applied in Russia? Organization Science, 14:686-706.

FIELD, A. 2009. Discovering statistics using SPSS ( $3^{\text {rd }}$ ed.) London: Sage.

FLORIDA, R. L. 2002. The rise of the creative class: And how it's transforming work, leisure, community, and everyday life. New York: Basic Books.

FORD, C. \& KUENZI, M. 2008. "Organizing” creativity research through historical analysis of foundational administrative science texts. In J. Zhou \& C.E. Shalley (eds.) Handbook of organizational creativity (pp. 6594). New York: Erlbaum.

GRANOVETTER, M.S. 1973. The strength of weak ties. American Journal of Sociology, 78:1360-1380. 
GUILFORD, J.P. 1950. Creativity. American Psychologist, 5:444-454.

HANLON, D. \& SAUNDERS, C. 2007. Marshalling resources to form small new ventures: Towards a more holistic understanding of entrepreneurial support. Entrepreneurship Theory and Practice, 31:619-641.

HOBDAY, M. 2000. The project-based organisation: An ideal form of managing complex products and systems? Research Policy, 29:871-893.

HURLEY, R.F. 1995. Group culture and its effect on innovative productivity. Journal of Engineering and Technology Management, 12:57-75.

ISAKSEN, S.G., LAUER, K.J., EKVALL, G. \& BRITZ, A. 2001. Perceptions of the best and worst climates for creativity: Preliminary validation for the situational outlook questionnaire. Creativity Research Journal, 13:171-184.

ISAKSEN, S.G. \& LAUER, K.J. 2002. The climate for creativity and change in teams. Creativity and Innovation Management, 11:74-86.

KANTER, R.M. 1988. Three tiers for innovation research. Communication Research, 15:509-523.

KHAZANCHI, S., LEWIS, M.W. \& BOYER, K.K. 2007. Innovation-supportive culture: The impact of organizational values on process innovation. Journal of Operations Management, 25:871-884.

KIVIMÄKI, M. \& ELOVAINIO, M. 1999. A short version of the team climate inventory: Development and psychometric properties. Journal of Occupational and Organizational Psychology, 72:241-246.

KOTTER, J.P. 2008. A sense of urgency. Boston: Harvard Business School Press.

KRATZER, J., LEENDERS, R. Th. A.J. \& VAN ENGELEN, J.M.L. 2009. The social network among engineering design teams and their creativity: A case study among teams in two product development programs. International Journal of Project Management, 28:428-436.

LEANA, C.R. \& VAN BUREN, H.J. 1999. Organizational social capital and employment practices. Academy of Management Review, 24:538-555.

LEENDERS, R. Th. A.J., VAN ENGELEN, J.M.L. \& KRATZER, J. 2003. Virtuality, communication, and new product team creativity: A social network perspective. Journal of Engineering and Technology Management, 20:69-92.

LOCKE, E.A. \& KIRKPATRICK, S.A. 1995. Promoting creativity in organizations. In C.M. Ford \& D.A. Gioia (eds.) Creative action in organizations: Ivory tower visions and real world voices (pp.115-120). London: Sage.

MARTINS, E.C. \& TERBLANCHE, F. 2003. Building organizational culture that stimulates creativity and innovation. European Journal of Innovation Management, 6:64-74.

MARTINS, E.C. \& MARTINS, N. 2007. An organizational culture model to promote creativity and innovation. SA Journal of Industrial Psychology, 28:58-65.

MATHISEN, G.E., EINARSEN, S., JØRSTAD, K. \& BRØNNICK, K.S. 2004. Climate for work group creativity and innovation: Norwegian validation of the team climate inventory (TCI). Scandinavian Journal of Psychology, 45:383-392.

MCLEAN, L.D. 2005. Organizational culture's influence on creativity and innovation: A review of the literature and implications for Human Resource Development. Advances in Human Resources Development, 7:226-246.

MILES, M.P., COVIN, J.G. \& HEELEY, M.B. 2000. The relationship between environmental dynamism and small firm structure, strategy and performance. Journal of Marketing: Theory and Practice, 8:63-74.

NUNNALLY, J.C. 1978. Psychometric theory. New York: McGraw-Hill.

O'REILLY, C.A., CHATMAN, J. \& CALDWELL, D.F. 1991. People and organizational culture: A profile comparison approach to assessing person-organization fit. Academy of Management Journal, 34:487-516.

OH, H., CHUNG, M-H. \& LABIANCA, G. 2004. Group social capital and group effectiveness: The role of informal socializing ties. Academy of Management Journal, 47:860-875.

OLDHAM, G.R. \& CUMMINGS, A. 1996. Employee creativity: Personal and contextual factors at work. Academy of Management Journal, 39:607-634.

PALLANT, J. 2005. SPSS survival manual: A step by step guide to data analysis using SPPS for Windows. Maidenhead: Open University Press. 
PATTERSON, M.G., WEST, M.A., SHACKLETON, V.J., DAWSON, J.F., LAWTHOM, R., MAITLIS, S., ROBINSON, D.L. \& WALLACE, A.M. 2005. Validating the organizational climate measure: Links to managerial practices, productivity, and innovation. Journal of Organizational Behavior, 26:379-408. PELLED, L.H., EISENHARDT, K.M. \& XIN, K.R. 1999. Exploring the black box: An analysis of work group diversity, conflict, and performance. Administrative Science Quarterly, 44:1-28.

PERRY-SMITH, J.E. 2006. Social yet creative: The role of social relationships in facilitating individual creativity. Academy of Management Journal, 49:85-101.

PERRY-SMITH, J.E. \& SHALLEY, C.E. 2003. The social side of creativity: A static and dynamic social network perspective. Academy of Management Review, 28:89-106.

PHEYSEY, D.C. 1993. Organizational cultures: Types and transformations. New York: Routledge. RAGAZZONI, P., BAIARDI, P., ZOTTI, A.M., ANDERSON, N., \& WEST, M. 2002. Italian validation of the Team Climate Inventory (TCI): A measure of team climate for innovation. Journal of Managerial Psychology, 17:325-336.

REITER-PALMON, R., ROBINSON-MORRAL, E.J., KAUFMAN, J.C. \& SANTO, J.B. 2012. Evaluation of self-perceptions of creativity: Is it a useful criterion? Creativity Research Journal, 24:107-114.

SCHEIN, E.H. 1990. Organizational culture. American Psychologist, 45:109-119.

SCHEIN, E.H. 2004. Organizational culture and leadership. San Francisco: Jossey-Bass.

SCHNEIDER, B. 2000. The psychological life of organizations. In N.M. Ashkanasy, C.P.M. Wilderon \& M.F. Peterson (eds.) Handbook of organizational culture and climate (pp. 21-36). Thousand Oaks: Sage. SETHIA, N.K. 1995. The role of collaboration in creativity. In C.M. Ford \& D.A. Gioia (eds.) Creative action in organizations: Ivory tower visions and real world voices (pp. 100-105). London: Sage.

SHALLEY, C.E. \& GILSON, L.L. 2004. What leaders need to know: A review of social and contextual factors that can foster or hinder creativity. Leadership Quarterly, 15:33-53.

SHALLEY, C.E. \& ZHOU, J. 2008. Organizational creativity research: A historical overview. In J. Zhou and C.E. Shalley (eds.) Handbook of organizational creativity (pp. 3-32). New York: Erlbaum.

TABACHNICK, B.G. \& FIDELL, L.S. 2001. Using multivariate statistics $\left(4^{\text {th }}\right.$ ed.) Boston: Allyn \& Bacon. TESLUK, P.E., FARR, J.L. \& KLEIN, S.R. 1997. Influences of organizational culture and climate on individual creativity. Journal of Creative Behavior, 31:27-41.

TIERNEY, P., FARMER, S.M. \& GRAEN, G.B. 1999. An examination of leadership and employee creativity: The relevance of traits and relationships. Personnel Psychology, 52:591-620.

TWISS, B.C. 1992. Managing technological innovation $\left(4^{\text {th }}\right.$ ed.) London: Pitman.

WASSERMAN S. \& FAUST, K. 2009. Social network analysis: Methods and applications. New York: Cambridge University Press.

WATSON, E. 2007. Who or what creates? A conceptual framework for social creativity. Human Resource Development Review, 6:419-441.

WEST, M.A. 1990. The social psychology of innovation in groups. In M.A. West \& J.L. Farr (eds.) Innovation and creativity at work: Psychological and organizational strategies (pp. 309-333). Chichester: Wiley.

WEST, M.A. 2002. Sparkling fountains and stagnant ponds: An integrative model of creativity and innovation implementation in work groups. Applied Psychology: An International Review, 51:355-424.

WHITLEY, R. 2006. Project-based firms: New organizational form or variations on a theme? Industrial and Corporate Change, 15:77-99.

WIERENGA, B. \& VAN BRUGGEN, G.H. 1998. The dependent variable in research into the effects of creativity support systems: Quality and quantity of ideas. MIS Quarterly, 22:81-87.

WOODMAN, R.W., SAWYER, J.E. \& GRIFFIN, R.W. 1993. Towards a theory of organizational creativity. Academy of Management Review, 18:293-321.

WUYTS, S., COLOMBO, M.G., DUTTA, S. \& NOOTEBOOM, B. 2005. Empirical tests of optimal cognitive distance. Journal of Economic Behavior and Organization, 58:277-302. 


\section{Appendix 1}

An example of the steps in calculating the dependent variable: employee creative output is presented in this appendix.

Example
One of the respondents in the sample was the (co)author of three articles published in ISI-ranked journals
during $2010-2011$. The first article was published in the International Journal of Management Reviews, which
had an impact factor (IF) of 2.612 . The second article was published in Economic and Industrial Democracy
and had an IF of 0.830 . The third article was published in the International Journal of Manpower, which had
an IF of 0.723 . The sum of these IFs is ( $2.612+0.830+0.723=) 4.165$ and the "mean IF of publications" of
this respondent is ( $4.165 / 3=) 1.388$.
To control for the field of research, the ISI database was scanned in order to determine the research field
to which each of the abovementioned journals relate. For the respondent in this example, the ISI database
shows that the International Journal of Management Reviews belongs to the "business" research field. Within
this research field, the mean IF of publications was 1.673 (as determined by ISI). The other two journals,
Economic and Industrial Democracy and International Journal of Manpower, both relate to the "industrial
relations" research field. The mean IF of publications in this field was 0.857 . The sum of the IFs of these three
research fields is ( 1 * $1.673+2$ * $0.857=) 3.387$. The "mean IF of all research fields" for this respondent is
(3.387 / $3=) 1.129$.
The calculated "mean IF of publications" (1.388) is now divided by the "mean IF of all research fields"
(1.129). For this respondent the "controlled mean IF of publications" is ( $1.388 / 1.129=) 1.229$. Finally, this
number was multiplied by the total number of papers (which was 3 ). This yielded a score of (1.229* $3=$ )
3.687 for this respondent, which is used as this respondent's score on the creative output variable.

